\title{
Microstructural-mechanical properties relationship in single polymer laminate composites based on polyamide 6
}

\author{
Shafagh D. Tohidi ${ }^{\mathrm{a}, *}$, Ana Maria Rocha ${ }^{\mathrm{a}}$, Nadya V. Dencheva ${ }^{\mathrm{b}}$, Zlatan Denchev $^{\mathrm{b}}$

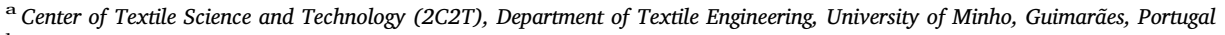 \\ ${ }^{\mathrm{b}}$ Institute for Polymers and Composites (IPC), Department of Polymer Engineering, University of Minho, Guimarães, Portugal
}

\section{A R T I C L E I N F O}

\section{Keywords:}

Single polymer composites

Polyamide 6

Knitted reinforcements

Flexural properties

Impact properties

Transcrystallinity

\begin{abstract}
A B S T R A C T
This paper studies the flexural and the impact properties of polyamide 6-based knitted reinforced single polymer composites (KSPCs) prepared by compression molding of powder-coated textile structures. To prepare matrix component, polyamide 6 microparticles (MPs) were synthesized by activated anionic ring-opening polymerization of $\varepsilon$-caprolactam in solution and then used for powder-coating of the knitted structures. The influence of the reinforcements' architecture, plies orientation, stacking order and fiber content on the final mechanical properties of KSPCs were investigated. Rib1 $\times 1$ and Jersey knitted structures were selected as reinforcements and treated by a stretching-annealing procedure to modify their mechanical properties. The anisotropic tensile and compression properties imparted by the knitted structures were found to be the major factors determining the impact and flexural behavior of KSPCs. Moreover, reinforcement's crossover points, the plies orientation and the presence of a transcrystalline layer at the matrix-reinforcement interface were identified as relevant parameters. The fracture mechanism of KSPCs was linked to the morphology and crystalline structure of the resulting composites and investigated by simulation and finite element analysis of knitted reinforcements.
\end{abstract}

\section{Introduction}

Nowadays there exists an increasing demand for lightweight and cost-effective thermoplastic materials that are easy to recycle by reprocessing without significant loss of useful properties. Energy savings and low emissions during the preparation of such materials, as well as their impact on the environment, are also taken into consideration [1]. Landfilling and incineration are the traditional ways to deal with the conventional composite materials waste due to the difficulties of the recycling process.

Single polymer composites (SPCs) are a novel class of composite materials in which the reinforcing filaments and the matrix are made, from the chemical point of view, of the same material [2]. Powder impregnation [3], hot compaction [2,4], overheating of fibers (i.e., partial melting) [5], film-stacking [6], and co-extrusion [7] are typical melt-processing techniques to fabricate SPCs. Their main advantages are the effective load transfer from the matrix to the reinforcement $[8,9]$ and the full recyclability by reprocessing [1]. The difference between the melting points of the matrix component and of the reinforcements in SPCs described as "processing window" is often very small because the material is chemically the same. There exist a number of studies dealing with the tensile properties and widening the processing window in polyamide 6 (PA6)-based SPCs [5,6,10-12].

To fabricate complex polymer composite structures with good impact energy absorption, specific molding condition is required in which the use of knitted reinforcements facilitates the thermoforming process [13]. Moreover, the near-net-shape configuration in knitted reinforcements causes better matrix impregnation in the molding procedure [13]. Studies on the influence of the knitted architecture on the flexural and impact behavior of polymer composites showed higher values while the reinforcing textiles are aligned unidirectionally, e.g., in wale direction [14-16]. However, no systematic studies exist on the relationship between the parameters of the reinforcing knitted textile structures and the morphology, structure and overall flexural and impact properties of PA6 laminate SPCs.

As far as other laminate composite types are concerned, KargerKocsis et al. [17] studied the transverse impact of Rib1 $\times 1$ knitted carbon fabric reinforced poly (ethyl methacrylate) (PEMA) and poly (ether ketone) (PEEK) composites with 35 and 51\% fiber volume fractions, respectively. The highest thickness-related perforation impact energy was found for the composites with PEEK matrix component $(\approx 15 \mathrm{~J} / \mathrm{mm})$ due to the high fiber content, high matrix ductility, and better fiber/matrix bonding. Pandita et al. [18] investigated the drop weight impact properties of Rib1 $\times 1$ knit/epoxy composites via

\footnotetext{
* Corresponding author.

E-mail address: Shafagh.project@gmail.com (S.D. Tohidi).
} 
ultrasonic analysis and X-ray tomography. Due to the high degree of anisotropy of these composites, the impact damage region was perpendicular to the weakest direction of the tensile properties (course direction). Khondker et al. [19] dealt with the effect of Rib1 $\times 1$ and Jersey architecture on the low-velocity drop weight impact of glass/ vinyl-ester composites. Their results showed that apparent mesh size ${ }^{1}$ of the knit structures decreased by the higher value of total loop density which provided better through-thickness-strength of the knit composite materials. Aktas et al. [20] investigated the impact behavior of epoxy laminate composites containing eight layers of glass textiles (Jersey and Rib1 $\times 1$ ) in which the maximum contact forces achieved for the Rib1 $\times 1$ reinforced composites. The failure modes were categorized by the fiber splitting and cracking at the level of penetration and perforation.

In the present study, the flexural and Izod impact properties of two types of PA6-based KSPCs reinforced by either Rib1 $\times 1$ or Jersey textiles were investigated. The composites were fabricated via compression molding of various plies of PA6 textiles powder-coated with MPs. The later were previously synthesized by means of activated anionic ring opening polymerization (AAROP) of $\varepsilon$-caprolactam (ECL) in solution. These MPs possess a lower melting point as compared to that of the PA6 reinforcing textiles usually fabricated by hydrolytic polymerization of ECL. Thus, the method for KSPC preparation described in this study provides conditions for a wider processing window avoiding the melting of the Rib1 $\times 1$ or Jersey textile reinforcements. This is decisive for the good mechanical performance of the new PA6-based KSPCs. The relation between the geometrical, tensile and compression properties of the knitted reinforcements and the flexural and impact properties of the final KSPCs was studied. The fracture mechanism was explained by the geometrical parameters of the reinforcements and the polymorphic crystalline structure of the KSPCs and precursors. Moreover, numerical simulations with a three-dimensional model based on the finite element method were performed to better assess the fracture mechanism of KSPCs. These simulations illustrated stress distributions in both knitted reinforcements while tensile displacements were applied in different directions.

\section{Experimental and test methods}

\subsection{Knitted reinforcements}

Two types of knitted fabrics were used as reinforcement i.e., Rib1 $\times 1$ and Jersey made out of air jet textured PA6 continuous filaments (160 dtex) of hydrolytic PA6, commercialized by Qualitat Técnica Téxtil (Portugal). All knitted structures were pre-washed with a non-ionic detergent solution at $40^{\circ} \mathrm{C}$ for $30 \mathrm{~min}$, and then rinsed with reverse osmosis water for another $15 \mathrm{~min}$. Then, the textiles were immersed in acetone for $30 \mathrm{~min}$ and dried for $2 \mathrm{~h}$ at $60^{\circ} \mathrm{C}$ to eliminate any soluble finish on the monofilament surface. To stabilize the dimensions and geometry of the knitted reinforcements, all samples were stretched to $30 \%$ of their original length along the two principal directions, using a screen stretching apparatus and then annealed with fixed ends at $170^{\circ} \mathrm{C}$ for $90 \mathrm{~min}$ in a specially designed metallic frame. The sample designation and properties of the knitted reinforcements before and after the stretching-annealing treatment are presented in Table 1.

\subsection{Reagents}

The ECL monomer of reduced moisture (AP-Nylon caprolactam) was delivered from Brüggemann Chemical (Germany). Before use, it was kept under vacuum for $1 \mathrm{~h}$ at $50^{\circ} \mathrm{C}$. As polymerization activator, Brüggolen C20 from the same company (C20) was used. According to

\footnotetext{
${ }^{1}$ Apparent mesh size is the inverse value of this volumetric total loop density or the integrity index and apparent stress transfer unit of the knit [31].
}

the manufacturer, it contains $80 \mathrm{wt} \%$ of blocked di-isocyanate in ECL. The initiator sodium dicaprolactamato-bis-(2-methoxyethoxo)-aluminate (DL) was purchased from Katchem (Czech Republic) and used without further treatment. The puriss grade of acetone and methanol, toluene and xylene solvents were purchased from Sigma-Aldrich (USA).

\subsection{Preparation of KSPCs}

The solution-precipitation AAROP of ECL to MPs was performed as described in detail previously [12,21-23]. Summarizing the preparation procedure, the lactam was dissolved in a $1: 1 \mathrm{v} / \mathrm{v}$ toluene/xylene mixture under nitrogen atmosphere refluxing the reaction mixture for 10-15 min. In several minutes, clear solutions were obtained and the components of the catalytic system DL and C20 were introduced in a molar ratio of $2: 1$. The reaction time was $1 \mathrm{~h}$, keeping the temperature in the $125-135^{\circ} \mathrm{C}$ range at constant stirring. The MPs were produced in the form of fine powder, separated from the reaction mixture by vacuum filtration, washed with methanol and dried.

The suspended level Ubbelohde viscometer was used to measure the average viscometric molecular weight $\mathrm{M}_{\mathrm{v}}$ of the as-prepared MPs in $97 \%$ sulfuric acid at a concentration of $0.2 \mathrm{~g} / \mathrm{dL}$ and constant temperature of $25^{\circ} \mathrm{C}$. The Mark-Houwink equation for PA6 was used with $\mathrm{K}=5.066 \times 10^{-4}$ and $\alpha=0.74$ [24]. A molecular weight of MPs was found to be about, ca. $36,500 \mathrm{~g} / \mathrm{mol}$, which was slightly below $\mathrm{M}_{\mathrm{v}}$ of the knitted textile reinforcements (ca. 39,500 g/mol). More details about the morphology and structure properties of the MPs without and with various payloads can be found elsewhere [12,21-23].

In summary, the KSPCs were produced by compression molding of R-A and J-A textile structures, uni or multidirectionally oriented, between which adequate quantities of MPs were introduced. A hydraulic hot press Moore (United Kingdom) equipped with a $70 \times 70 \times 2 \mathrm{~mm}$ mold was used for composite consolidation. Three fiber volume fractions $\mathrm{V}_{\mathrm{f}},{ }^{2}$ namely, 15, 20 and $25 \%$ were considered. Applying volume fractions above $25 \%$ require higher plies number in the ply set. Any attempt to consolidate such ply sets by compression molding caused a rupture in the embedded knitted structures. Thus, for the preparation of laminate KSPCs of $k$ plies, the respective MPs were divided into $(k+1)$ equal portions used for powder coating of the knitted structures. These ply sets were subjected to a pressure of $5 \mathrm{MPa}$ for $10 \mathrm{~min}$ at $215{ }^{\circ} \mathrm{C}$ (a temperature below the $T_{m}$ of reinforcements and above that of the MPs), followed by a cooling down to $50{ }^{\circ} \mathrm{C}$, at a $40{ }^{\circ} \mathrm{C}$. $\mathrm{min}^{-1}$ rate. This preparation procedure was denominated as powder-coating/compression molding (PCCM) technique. Table 2 describes the sample designation and the processing characteristics of the KSPCs studied in this work. The test samples used for the mechanical tests were laser cut according to the respective test standards from one and the same composite plate to ensure reproducibility.

\subsection{Sample characterization}

The fracture mechanism and the interfacial bonding were studied by scanning electron microscopy (SEM) performed in a NanoSEM -200 apparatus of FEI Nova (USA) using mixed secondary electron/backscattered electron in-lens detection. The cryofractured specimens were covered with a film of Au-Pd (80-20 wt \%) in a high-resolution sputter coater.

To visualize and analyze optical microscopy images of monofilaments in original textile reinforcements prepared by microtoming, an Olympus BH-2 light microscope (Japan) equipped with Leica Application Suite 4 software was used.

The X-ray diffraction pattern of the precursors and of the final

\footnotetext{
${ }^{2} V_{f}$ value is determined according to $V_{f}=\frac{A_{w} \cdot N}{\rho_{f} \cdot t} \times 100$, where $A_{w}\left(g / m^{2}\right)$ is the area density of the textile reinforcement, $N$ is the number of plies, $\rho_{f}\left(\mathrm{~g} / \mathrm{m}^{3}\right)$ is the density of the PA6 filaments and $t$ in (m) is the laminate thickness [32].
} 
Table 1

Designation and properties of the knitted fabric reinforcements.

\begin{tabular}{|c|c|c|c|c|c|c|c|c|}
\hline Reinforcement type & Treatment & Sample Designation & WPC & CPC & Stitch density & Areal weight $\left(\mathrm{g} / \mathrm{m}^{2}\right)$ & Thickness (mm) & Bulk density $\left(\mathrm{g} / \mathrm{cm}^{3}\right)$ \\
\hline \multirow[t]{2}{*}{ Jersey } & No & $\mathrm{J}$ & 16 & 30 & 480 & $160 \pm 4$ & $0.54 \pm 0.01$ & 0.296 \\
\hline & Yes & $\mathrm{J}-\mathrm{A}$ & 15 & 25 & 375 & $102 \pm 2$ & $0.41 \pm 0.01$ & 0.248 \\
\hline \multirow[t]{2}{*}{$R i b 1 \times 1$} & No & $\mathrm{R}$ & 16 & 25 & 400 & $208 \pm 4$ & $0.79 \pm 0.01$ & 0.263 \\
\hline & Yes & R-A & 13 & 18 & 234 & $108 \pm 2$ & $0.60 \pm 0.01$ & 0.180 \\
\hline
\end{tabular}

$\mathrm{WPC}=$ Wale per centimeter, $\mathrm{CPC}=$ Course per centimeter.

Table 2

Description of the KSPCs composite laminates.

\begin{tabular}{lllll}
\hline $\begin{array}{l}\text { KSPCs } \\
\text { designation }\end{array}$ & $\begin{array}{l}\text { Knitted } \\
\text { reinforcement } \\
\text { architecture }\end{array}$ & $V_{f},(\%)$ & $\begin{array}{l}\text { Number of } \\
\text { Plies }\end{array}$ & Plies Orientation \\
\hline PU-J $\left(^{\mathrm{a}}\right)-15$ & Jersey, after & 15 & 3 & Unidirectional $^{\mathrm{a}}$ \\
PU-J $\left({ }^{\mathrm{a}}\right)-20$ & stretching and & 20 & 5 & \\
PU-J $\left({ }^{\mathrm{a}}\right)-25$ & annealing & 25 & 6 & Multidirectional $^{\mathrm{b}}$ \\
PM-J ( $\left.{ }^{\mathrm{b}}\right)-15$ & & 15 & 3 & Unidirectional $^{\mathrm{a}}$ \\
PU-R $\left({ }^{\mathrm{a}}\right)-15$ & Rib1 $\times 1$, after & 15 & 3 & \\
PU-R ( $\left.{ }^{\mathrm{a}}\right)-20$ & stretching and & 20 & 4 & Multidirectional $^{\mathrm{b}}$ \\
PU-R ( $\left.{ }^{\mathrm{a}}\right)-25$ & annealing & 25 & 5 & \\
PM-R ( $\left.{ }^{\mathrm{b}}\right)-15$ & & 15 & 3 & \\
\hline
\end{tabular}

${ }^{\text {a }}$ Unidirectional ply sets of knitted textile reinforcements in which 0 and 90 stand for wale-wise and course-wise directions respectively.

b Multidirectional ply sets of knitted textile reinforcements via combination of wale (0), course (90) and bias (45) orientations. In these samples, the designations of $(0)$ and (90) represent the stacking orders of $0 / 45 / 0$ and 90/45/90, respectively.

laminate composites were performed in a Bruker D8 Discover $\theta-\theta$ diffractometer working with $\mathrm{Cu} \mathrm{K \alpha}$ radiation $(=1.541 \AA$ ). The patterns were collected for all samples in the $2 \theta$ range of $5-45^{\circ}$ with a step time of $2 \mathrm{~s}$ and step size of $0.1 \mathrm{deg} \cdot \mathrm{min}^{-1}$. Curve fitting of the XRD patterns was carried out as previously discussed [25] using a commercial peakfitting software. The XRD crystallinity index $X_{c}^{X R D}$ was calculated according to:

$X_{c}^{X R D}, \%=\frac{\sum A_{c}}{\sum A_{c}+\sum A_{a}}$

where $\sum A_{c}$ is the integrated area underneath the respective crystalline peaks and $\sum A_{a}$ is the integrated area of the amorphous halo(s).

\subsection{Mechanical characterization}

Tensile tests of all knitted fabrics were carried out based on ASTM D5034 (grab test) in an Instron 4505 machine with a standard load cell of $2.5 \mathrm{kN}$ at a crosshead speed of $2 \mathrm{~mm} / \mathrm{min}$ and the sample size was $150 \times 100 \mathrm{~mm}$. The composite samples were stored for $5 \mathrm{~h}$ in a controlled environment at $23^{\circ} \mathrm{C}$ before testing.

A dynamical and mechanical analysis (DMA) of all non-treated and treated knit reinforcements (isothermal mode) was performed on a DMA 8000 (Perkin Elmer, USA), in compression mode, according to an internal method based on standard ASTM D4065-01. The storage modulus and loss tangent was measured in an isothermal condition $\left(30^{\circ} \mathrm{C}\right)$. The viscoelastic parameters, elastic (storage) modulus $\left(\mathrm{E}^{\prime}\right)$, viscous (loss) modulus ( $\left.\mathrm{E}^{\prime \prime}\right)$ and tangent delta $(\tan \delta$ ) were calculated using the following equations [26].

$\left\{\begin{array}{c}E^{\prime}=\frac{\sigma_{0}}{\varepsilon_{0}} \times \cos \delta \\ E^{\prime^{\prime}}=\frac{\sigma_{0}}{\varepsilon_{0}} \times \sin \delta \\ \delta=\tan ^{-1} \frac{E^{\prime^{\prime}}}{E^{\prime}} \\ \left|E^{*}\right|=E^{\prime}+i E^{\prime^{\prime}}\end{array}\right.$ where the phase angle $\delta$ (rad) is the phase difference between the dynamic stress and strain.

The flexural properties of the KSPCs were evaluated in an Instron 4505 testing machine according to ASTM D 790-03. In this three-point loading method, tests were performed using a load cell of $1 \mathrm{kN}$, at a constant speed of $2 \mathrm{~mm} / \mathrm{min}$, and a distance between the points of support of $40 \mathrm{~mm}$. The flexural modulus, $\mathrm{E}_{\mathrm{f}}(\mathrm{GPa})$, flexural strength, $\sigma_{\mathrm{f}}$ $(\mathrm{MPa})$ and flexural strain, $\varepsilon_{\mathrm{f}}(\%)$ were calculated using the following equations:

$\left\{\begin{array}{c}E_{f}(G P a)=\frac{L^{3} \cdot m}{4 b d^{3}} \\ \sigma_{f}(\mathrm{MPa})=\frac{3 \mathrm{PL}}{2 b d^{2}} \\ \varepsilon_{f}(\%)=\frac{6 \mathrm{D} d}{L^{2}}\end{array}\right.$

where $L$ is the distance between the points of support, $m$ is the slope of the force-deflection curve, $b$ and $d$ are the width and the thickness of the sample ( $\mathrm{mm}$ ), respectively, D is the maximum deflection in $\mathrm{mm}$ and $\mathrm{P}$ is the applied force $(\mathrm{N})$.

The impact strength of the composite materials was evaluated using an Izod pendulum impact tester, according to ASTM D 256-04. Tests were performed with unnotched samples and $22 \mathrm{~mm}$ height at strike point. The impact strength $\left(\mathrm{I}_{S}\right)$ is determined by the impact energy absorbed by the sample cross-section, according to equation:

$I_{S}\left(\frac{K J}{m^{2}}\right)=\frac{E_{\text {composite }}-E_{i}}{\mathrm{~A}}$

where $E_{i}$ and $E_{\text {composite }}$ are the impact energies registered without and with the sample, respectively, and A is the area of the sample.

\subsection{Real-size simulation of reinforcements}

To simulate real-size R-A and J-A reinforcements, the base points of their kernel geometry was drawn via image analysis of ten digitalized microscopic images from the technical surface using MATLAB ${ }^{\circ}$ software. Afterward, the determined kernel geometry was imported to the SolidWorks (Dassault system, France) software to sweep the yarn profile along it. Three major hypotheses were taken into consideration for the simplification of the simulation procedure: (i) The filament cross section was determined as elliptical; (ii) The constant sweeping of elliptical cross-section through the kernel geometry and (iii) no dimensional deformation occurred at crossover points. To evaluate the contact situation on each crossover point, a virtual clash test was performed.

\subsection{Finite element analysis}

Parametric study on stress distribution along stretched-annealed knitted reinforcements was carried out using finite element analysis. A $10 \times 10 \mathrm{~mm}$ constitutive model considering both filament's directional properties was implemented using the implicit mode of ABAQUS Standard $^{\mathrm{TM}}$ (Dassault system, France) software, through a user material subroutine. The four-node tetrahedral element (C3D4) with the edge seeding of 0.05 was applied through the entire models. The shape functions can be found in Ref. [27]. 

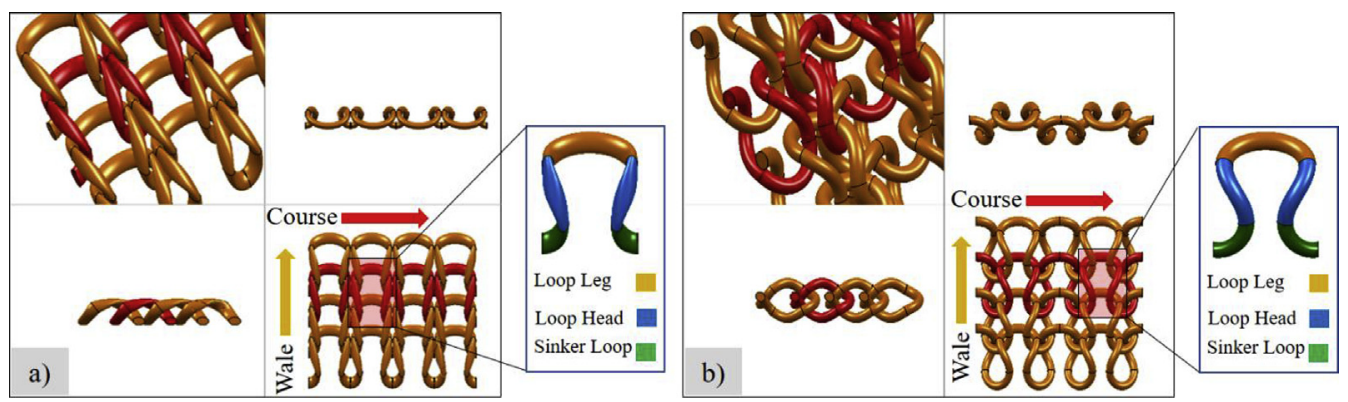

Fig. 1. Simulated real size annealed knit structures detailed by loop unit-cell configuration a) Jersey and b) Rib1 $\times 1$ reinforcements.

\section{Results and discussion}

\subsection{Tensile properties of knitted reinforcements}

As the tensile behavior of the knitted reinforcements clearly affects the mechanical properties of the composite laminates, single plies of Jersey and Rib $1 \times 1$ fabrics were tested, before and after the stretchingannealing treatment, in wale $\left(0^{\circ}\right)$, bias $\left(45^{\circ}\right)$ and course $\left(90^{\circ}\right)$ directions. As it can seen in Fig. 2a-c, the stretching-annealing treatment applied to the knitted reinforcements at different angles, led to a significant increase of their tensile stiffness and strength and to a decrease in elongation. Straining of J-A reinforcement resulted in a higher tensile stiffness (E) improvement of $80 \%$ and $500 \%$ at $0^{\circ}$ and $90^{\circ}$, respectively, when compared to the R-A structures. The lowest stiffness was registered at $45^{\circ}$ direction in J-A and R-A reinforcements (Fig. 2a). The reason for the low E modulus of J (45)-A and R (45)-A samples was the uneven stress distribution along their structure. In section 4 the finite element analysis performed will better explain this behavior. The J-A reinforcements displayed superior tensile strength in all directions than R-A structures in which the highest improvement factor of $171 \%$ was calculated in the course $\left(90^{\circ}\right)$ direction (Fig. 2b). The J-A reinforcements showed lower elongation than the R-A structures (Fig. 2c).

Fig. $2 \mathrm{~d}$ shows the anisotropy on the tensile stiffness of the J-A and RA reinforcements. Higher anisotropy was presented by the J-A reinforcements. The annealed Rib $1 \times 1$ reinforcements shown in Fig. 1 are symmetric on the technical back and front faces although the J-A reinforcements have different architecture on either face. Apparently, the more anisotropic behavior of J-A reinforcements is related to their less symmetric structure, when they are subjected to a bi-dimensional strain during the annealing procedure.

\subsection{Knitted reinforcements compression study by DMA}

The isothermal compression properties of all knitted reinforcements were evaluated by DMA. In compression mode, an axial load was applied to the one-dimensional knitted reinforcements held between two parallel plates whereas bulk compression produces a three-dimensional change. The uniaxial compression forced the stretched-annealed reinforcement textile to buckle.

The elastic storage modulus $E^{\prime}$ as a measure of the elasticity of the material is proportional to the energy stored during a loading cycle. It represents the ability of the material to store energy and is similar to the elastic modulus for a single, rapid stress at low load and reversible deformation [26]. The viscous loss modulus $E^{\prime \prime}$ is defined as being proportional to the energy dissipated during a loading cycle. The $\tan \delta$ is a measure for material's mechanical damping or internal friction in a viscoelastic system. When $\tan \delta>1$, the material can be considered more viscous than elastic. On the other hand, $\mathrm{E}^{\prime}$ is higher than $E^{\prime \prime}$ while $\tan \delta<1$.
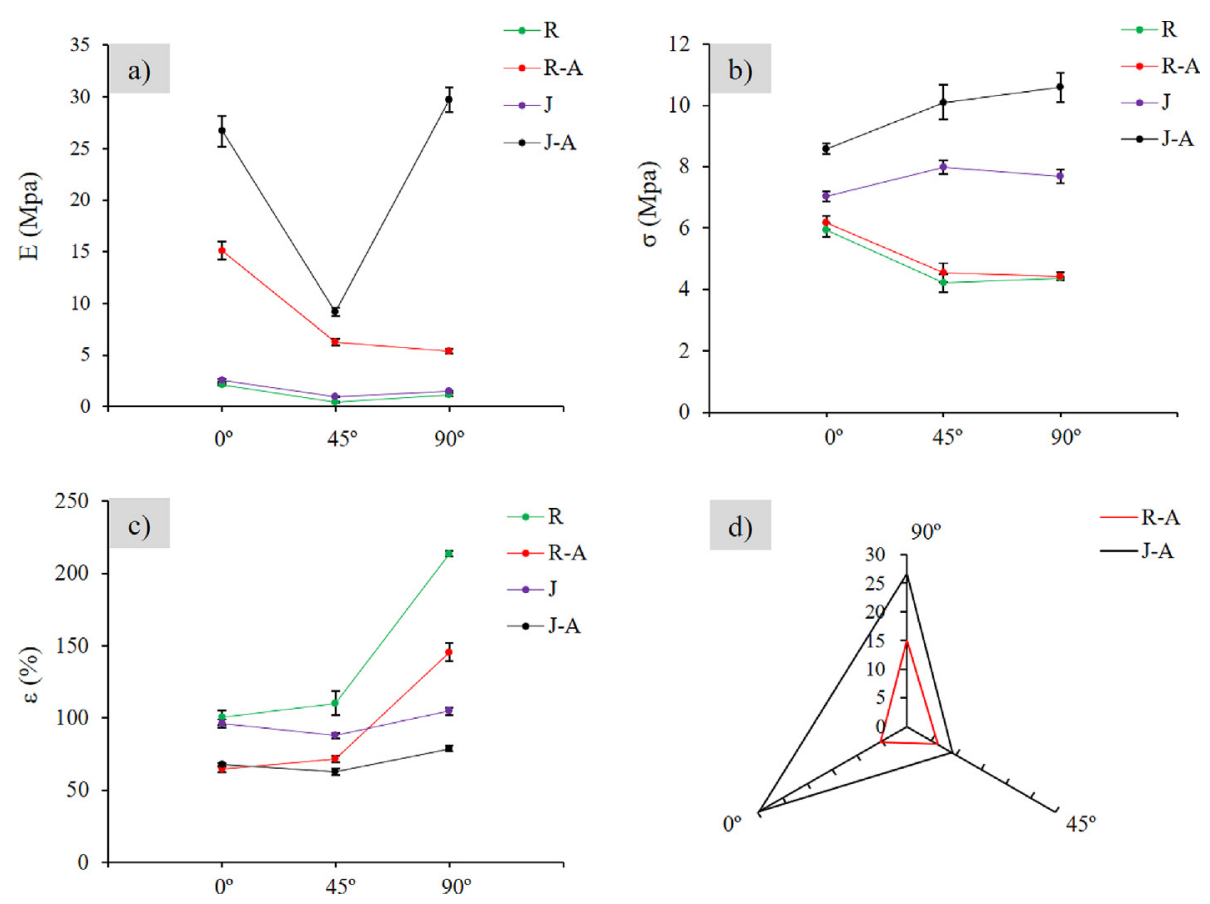

Fig. 2. Tensile properties of knitted reinforcements before and after stretching-annealing treatment: a) tensile stiffness; b) tensile strength; c) tensile strain at different angles. d) Anisotropy of "treated" knitted reinforcements-dependence of tensile stiffness on the loading direction. The designations are presented in Table 1. 

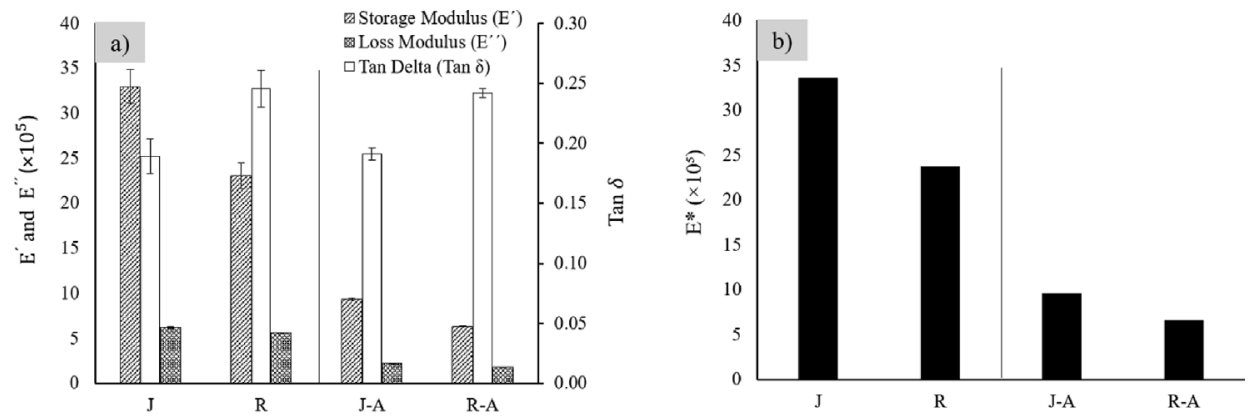

Fig. 3. Viscoelastic parameters of knit reinforcements before and after the stretching-annealing treatment; a) E, E', E'” and $\delta$; b) $E^{*}$.
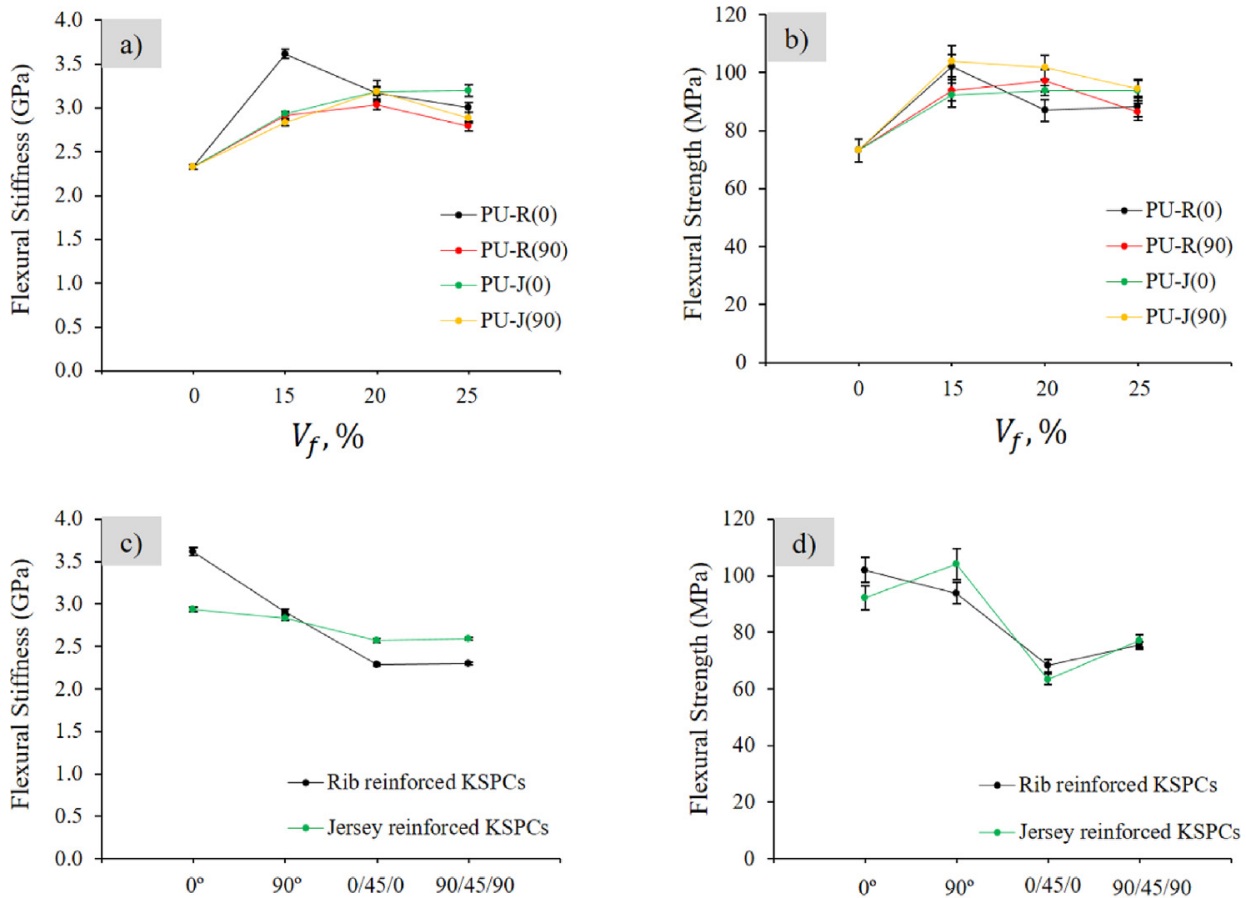

Plie orientation and stacking order

Plie orientation and stacking order

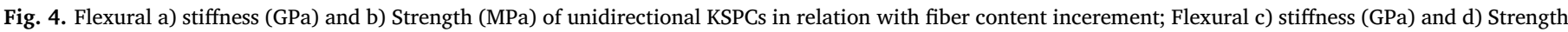
(MPa) of multidirectional KSPCs reinforced with 15\% fiber volume fraction. The designations are presented in Table 2.

Fig. 3a-b shows that the stretching-annealing treatment clearly affected the viscoelastic compression parameters of the knitted reinforcements, significantly decreasing the elastic $\left(E^{\prime}\right)$ and viscous $\left(E^{\prime \prime}\right)$ modulus and the complex compression modulus ${ }^{3}\left(E^{*}\right)$ of the treated reinforcements. The $\mathrm{J}$ structures showed significantly higher storage $\left(E^{\prime}\right)$ and loss $\left(E^{\prime \prime}\right)$ modulus than the Rib1 $\times 1$ reinforcements. Although the $\tan \delta$ of Rib1 $\times 1$ architectures before and after the stretching-annealing treatment were higher than Jerseys. The reason can be related to the higher bulkiness and symmetric pattern of Rib1 $\times 1$ reinforcements causing partly more dissipation and less storing of the implied loads in the fabric structure. Otherwise, Jersey textile is more elastic during loading and has more potential to store the load rather than to dissipate it. Fig. 3b demonstrates the superior $\mathrm{E}^{*}$ modulus of the Jersey reinforcements before the stretching-annealing treatment. After this procedure, the complex moduli of both reinforcements became similar. The reasons could be related to decreasing the stored energy and energy dissipation of treated knitted reinforcements provoked by stiffening of the monofilaments after stretching-annealing treatment.

\footnotetext{
${ }^{3}$ The $\mathrm{E}^{*}$ is given by the ratio between the stress and the strain amplitudes and represents the overall resistance of the material to compression.
}

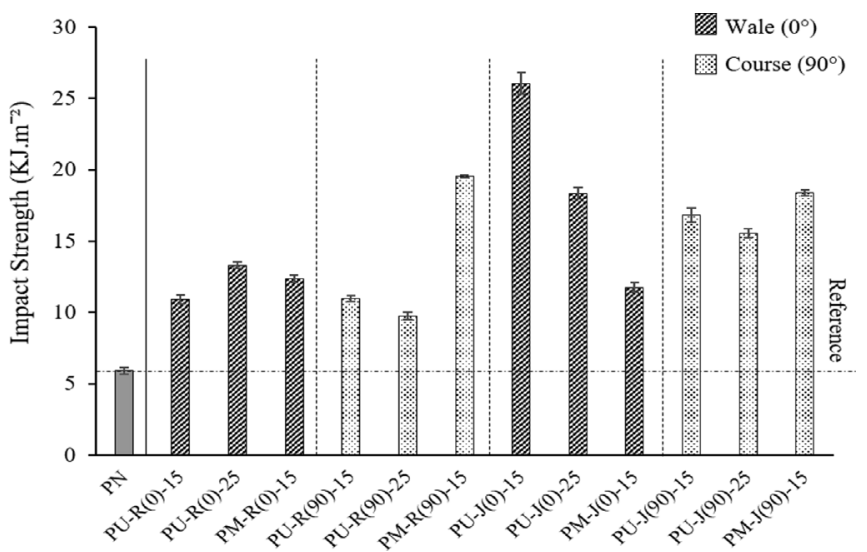

Fig. 5. Comparison of the Izod impact strength of uni-or multidirectional KSPCs with respect to the knitted architecture, fiber volume fraction, plies orientation and plie stacking order. 

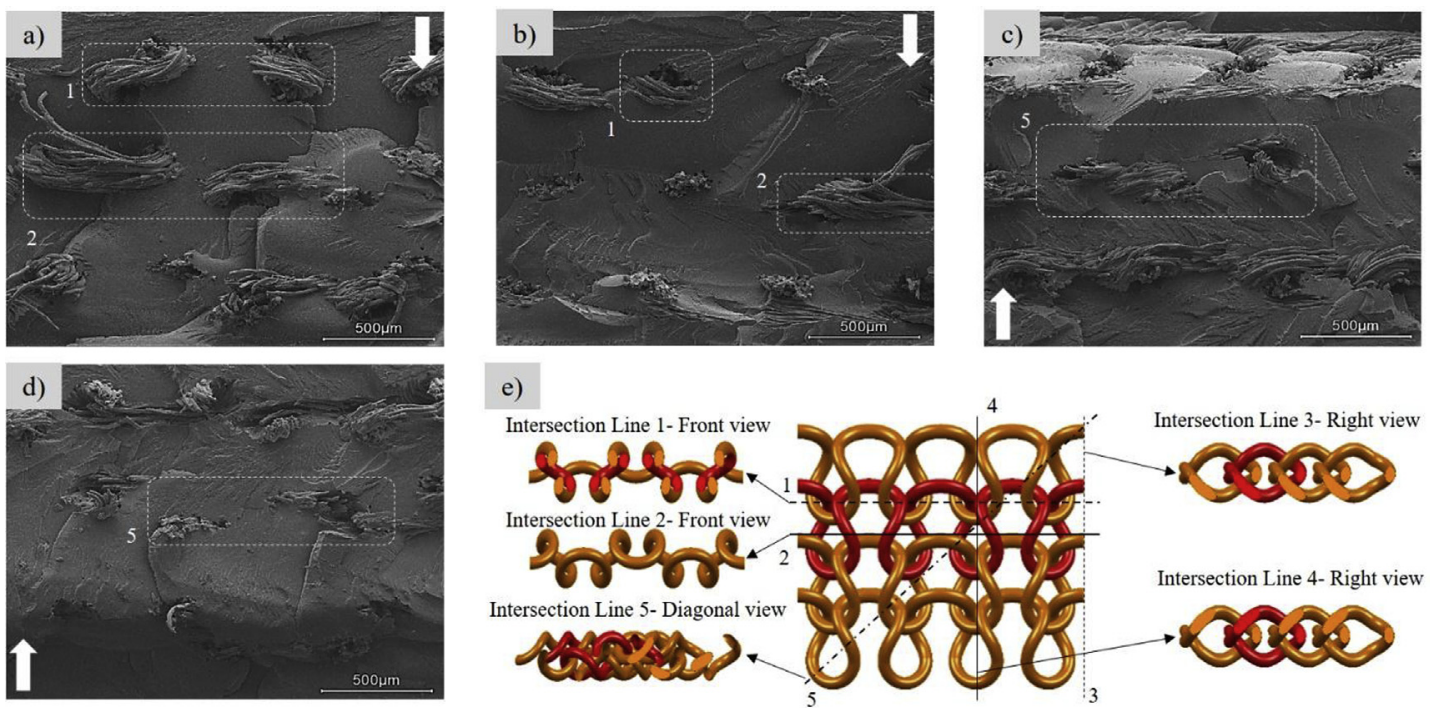

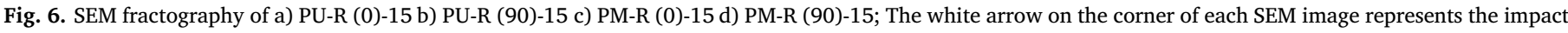

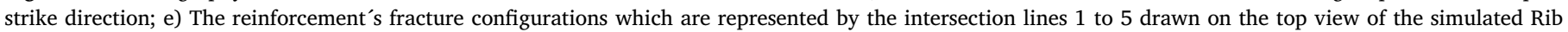
$1 \times 1$ structure.

\subsection{Flexural properties of KSPCs}

The influence of the knitted architecture (J-A and R-A), fiber volume fraction $(15 \%, 20 \%$, and $25 \%)$, ply orientation $\left(0^{\circ}, 90^{\circ}\right)$ and stacking order $(0 / 45 / 0,90 / 45 / 90)$ on the flexural properties of KSPCs is shown on Fig. 4a-b. Compared to the neat matrix (PN) reference sample, all unidirectional stacked R-A and J-A reinforced KSPCs improved the flexural stiffness and strength to ca. 56\% and 38\% respectively (Fig. 4a). Applying J-A structures in KSPCs showed higher flexural rigidity, about $13 \%$ than those reinforced with R-A. The obtained results demonstrate that composites with $15 \% V_{f}$ are higher resistant to flexural loads (Fig. 4b). For the same fiber volume fraction, the KSPCs with J-A structures embedded in the course direction $\left(90^{\circ}\right)$ showed the highest flexural strength ( $\sim 100 \mathrm{MPa}$ ). The flexural stiffness (Fig. $4 \mathrm{a})$ and strength (Fig. 4b) of unidirectional stacked KSPCs was not significantly changed by fiber content variation, except for the R-A laminates wherein an increase from 15 to $20 \%$ led to a significant decrease in the flexural stiffness (14\%) and strength (17\%). Fig. 4c-d compares the flexural properties of multidirectional R-A and J-A reinforced KSPCs with $15 \% V_{f}$. As it can seen from Fig. 4c-d, the multidirectional stacking, clearly deteriorated the flexural properties of KSPCs.

\subsection{Impact strength of KSPCs}

Fig. 5 shows the impact strength $\left(I_{s}\right)$ of the uni-or multidirectional KSPCs. The $I_{s}$ value of the neat matrix (PN), is also represented for reference. As it can seen in Fig. 5, embedding knitted reinforcements improved 2-5 times the impact resistance of anionic PA6 matrix. The impact strength of KSPCs with wale-oriented J-A reinforcements $\left(0^{\circ}\right)$ and $15 \%$ fiber content increased up to $340 \%$ when compared to the PN reference. Moreover, the unidirectional J-A reinforced KSPCs showed better impact resistance than the R-A reinforced ones. Increasing the fiber content from 15 to $25 \%$ led to a decrease of the composite's impact strength, except for the wale-oriented R-A reinforced KSPCs. This decrease is highly significant in the wale-oriented J-A reinforced composites. The reason can be explained by the structural analysis of knitted reinforcements and crystalline morphology at the interface region performed in next sections. The KSPCs with 90/45/90 stacking order showed superior impact strength than those with plies embedded with 0/45/0 order. Unlike PM-J (0)-15 sample, multidirectional plies orientation modified the impact strength of KSPCs in that corresponding direction.

\section{Impact failure analysis}

To better understand the impact behavior of KSPCs, scanning electron microscopy (SEM) studies were performed. Fig. 6a-d shows SEM images of impact failure cross-sections of uni-or multidirectional R-A reinforced KSPCs with $15 \% V_{f}$. For better visualization, the failure analysis, the fracture locations were illustrated by the intersection lines 1 to 5 drawn on the top view of the simulated R-A structure (Fig. 6e). The fractured surface of PU-R (0)-15 specimen demonstrated the emergence of loop heads and sinker loops due to the initiation of breakage from the highly-stressed crossover points. In the PU-R (90)-15 sample, the different plies' orientation led to a distinct fractured surface configuration, in which the loop crossover points were responsible for the impact failure (Fig. 6a-b and lines 1 and 2 in Fig. 6e). The fractured surfaces of multidirectional R-A reinforced KSPCs is illustrated in Fig. $6 c-d$. Fig. $6 c-d$ show the appearance of all loop components, such as, loop head, leg and sinker loop, in the fractured surface cross-section of multidirectional R-A reinforced KSPCs that can be correlated with the intersection lines 5 in Fig. 6e. Due to this observation, high impact strength for unidirectional R-A reinforced KSPCs can be linked to the better distribution of impact loads.

From these studies, it is apparent that the loops crossover points are primary factor for KSPCs failure. It was assumed that the number of crossover points per unit area of the stretched-annealed knitted reinforcements could explain the superior impact resistance of J-A reinforced KSPCs. It was found that the number of crossover point per unit area $(10 \times 10 \mathrm{~mm})$ was 612 and 432 units for J-A and R-A reinforcements, respectively. Thus, the higher number of crossover points in J-A structure would lead to lower impact properties of J-A reinforced KSPCs, which is in contradiction with the obtained experimental results.

Geometrical study of the stretched-annealed knitted reinforcements is not the only explanation for the different flexural and impact properties of reinforced KSPCs. Meanwhile, the distribution of tensile and compression stress along the test sample during bending and Izod impact experiments was investigated to reveals the causes of KSPCs mechanical failure. Fig. 7a-c shows typical beam flexural test specimens in 

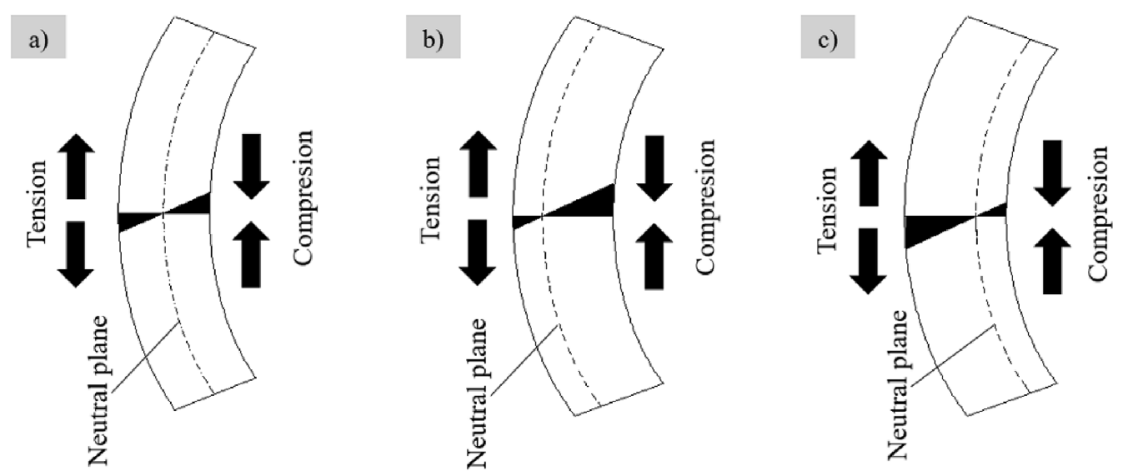

Fig. 7. Schematic of a beam at the moment of bending with a) symmetrical Stress distribution; b-c) unsymmetrical stress distribution.
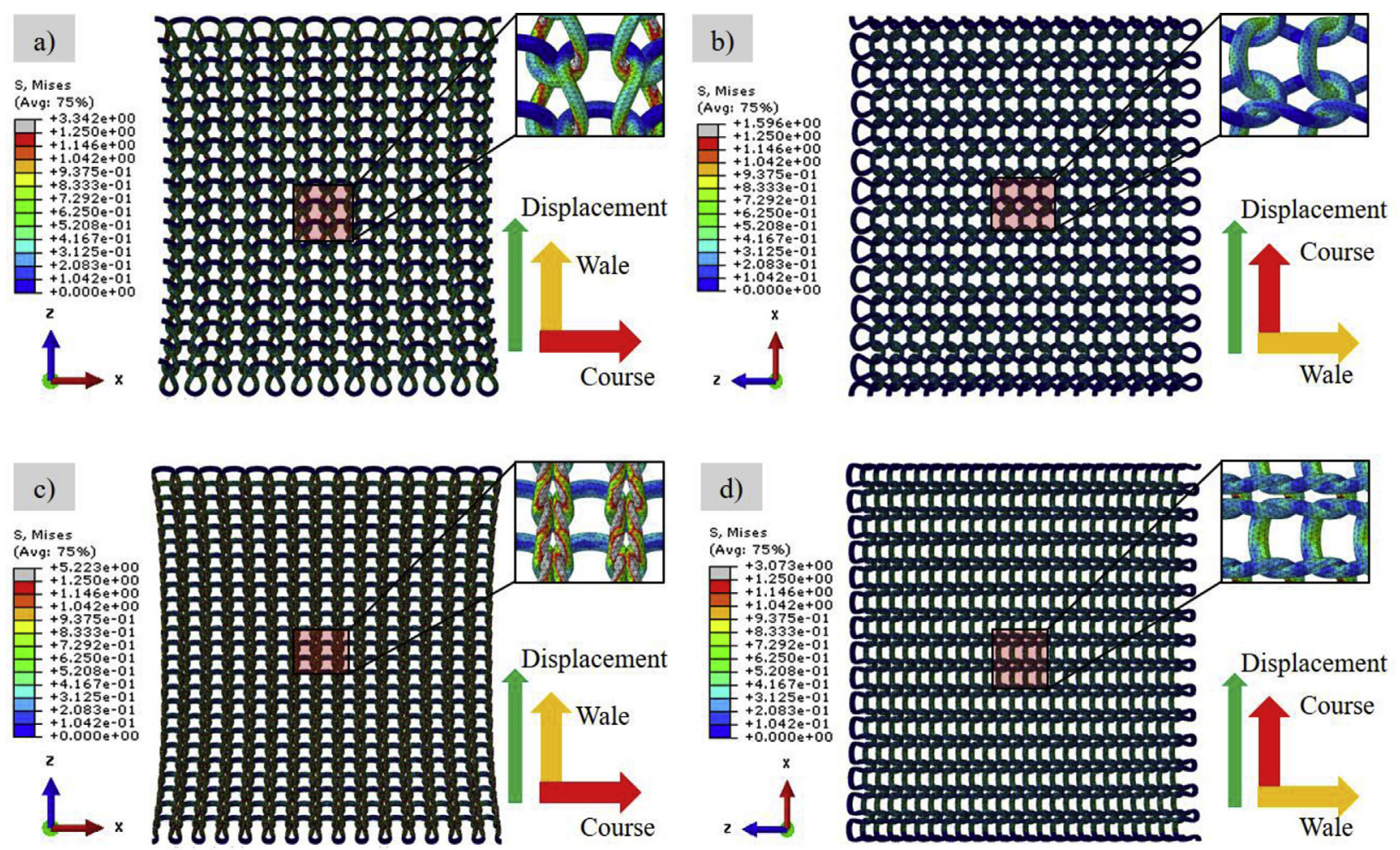

Fig. 8. Finite element analysis of $10 \times 10 \mathrm{~mm}$ treated knitted reinforcements with $2 \mathrm{~mm}$ displacement in a) R (0)-A; b) R-(90)-A; c) J (0)-A; d) J (90)-A.

which a bending moment causes a beam to bend. The material in outside boundary, beyond the neutral plane, ${ }^{4}$ is extended although the inside boundary, below the neutral plane, is contracted [28]. In the elastic range, the material at the outside and the inside edges are in tension and compression respectively. The stress distributions along tension and bended sides should be kept in the balance until reaching to yield flexural strength. The tension and compression stresses toward the surfaces proportionally increases while the neutral plane maintains in the middle of cross-section (Fig. 7a). On the contrary, asymmetric stress distribution can be contributed by shifting neutral plane due to the better material balances on either side of it (Fig. $7 \mathrm{~b}-\mathrm{c}$ ). Due to the application of same matrix component with identical molding condition, a comparative study on tensile and compression behavior of knit structure particularly could provide a logical proof on failure mechanism and better flexural and Izod impact properties of J-A reinforced KSPCs.

\footnotetext{
${ }^{4}$ There can only be one plane through the beam that isn't either longer or shorter than it was before the bend which is called neutral plane [28].
}

According to the obtained DMA data analysis, J-A reinforcements had slightly higher $\mathrm{E}^{*}$ modulus than R-A structures (see Fig. 3b). Despite the position of the neutral plane and related to the superior tensile properties of J-A than R-A reinforcements in the two principal directions, the impact properties of the composite beam depended mainly on the tensile properties of the knit structures (see Fig. 2).

An in-depth parametric study of the treated knitted reinforcement's tensile behavior in relation with impact failure mechanism was performed via finite element analysis subjected to a $2 \mathrm{~mm}$ on-axis and offaxis uniaxial tensile displacements (Fig. 8a-d). Comparing their "von Mises stress" distributions demonstrated that the knit loops in wale $\left(0^{\circ}\right)$ direction are more tolerant to the in-plane tensile loads. The maximum distortion energy calculated on the crossover points of treated knitted reinforcements demonstrates the reason of failure at those points. (see Fig. 6).

Comparing the equivalent tensile stress of treated knitted reinforcements evidenced that J-A had higher "von Mises yield stress" in wale (56\%) and course (93\%) directions than the R-A structures. Moreover, all loop parts, such as loop heads, legs and sinker loops in J-A structures were involved in bearing the tensile loads. On the other 

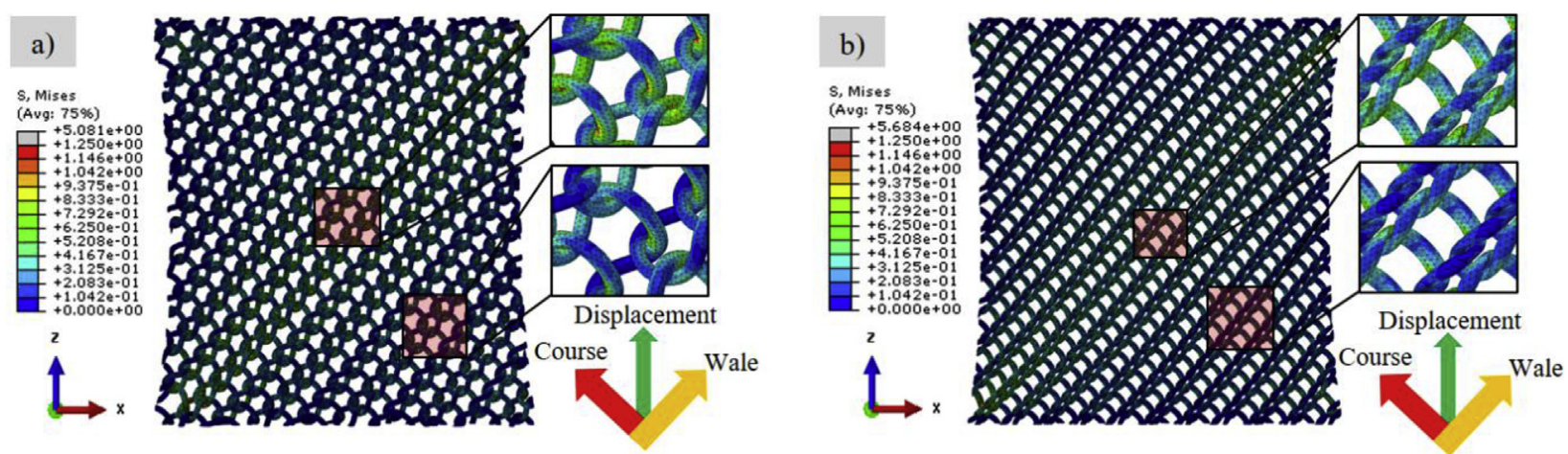

Fig. 9. Finite element analysis of $10 \times 10 \mathrm{~mm}$ stretched-annealed knitted reinforcements with $2 \mathrm{~mm}$ displacement in a) R (45)-A; b) $\mathrm{J}$ (45)-A.
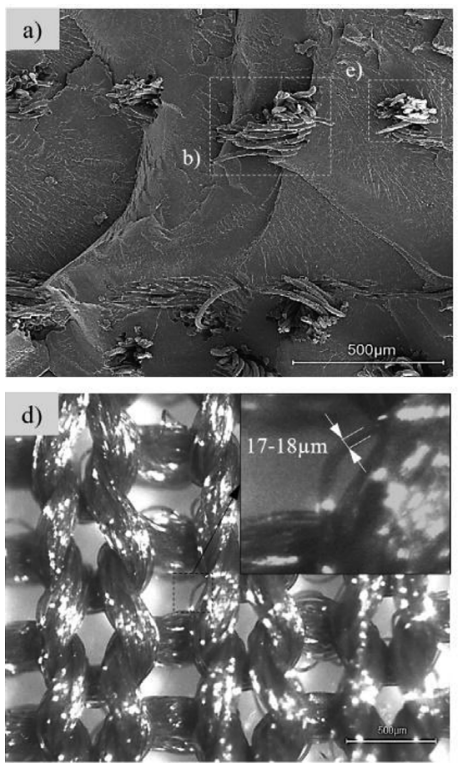
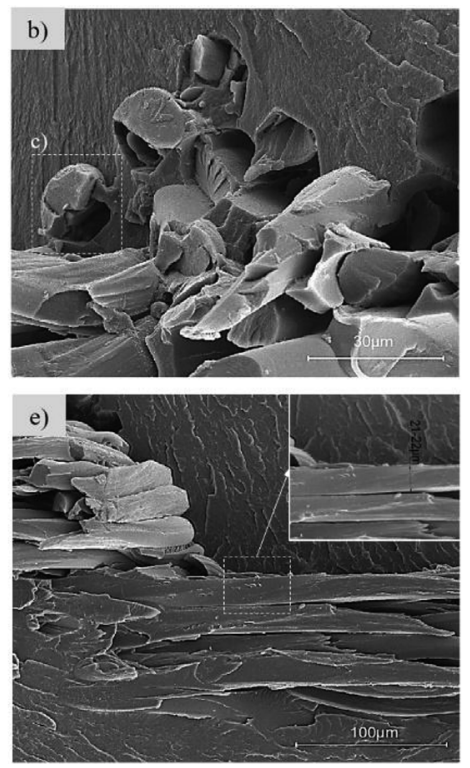
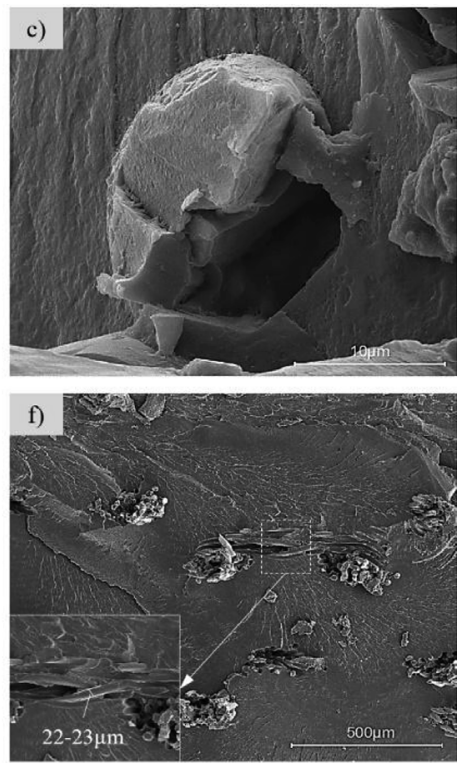

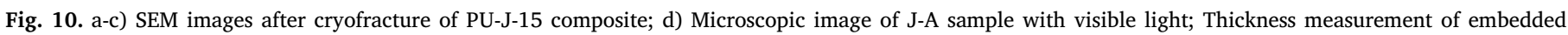
monofilaments in SEM images after cryofracture of e) PU-J-15 f) PU-R-15 composites.

hand, in the case of R-A structures, only loop legs and loop heads contributed to support the tensile stresses in wale and course directions, respectively. Due to this fact, it can be deduced that J-A reinforcements distribute better the tensile stresses than R-A structures, causing a high impact resistance of the J-A reinforced KSPCs.

Applying diagonal displacement on all treated knitted reinforcements led to the crosswise concentration of tensile stresses (Fig. 9a-b), wherein different equivalent tensile stresses on the center and sides of the knitted reinforcement were observed. At the beginning of impact collision, the unidirectional embedded reinforcement on top ply propagate the forces and then transmits them to the middle multidirectional plie. Because of highly stress concentration in middle ply $\mathrm{J}$ A than R-A structures, the impact forces are not damped properly in J-A reinforced KSPCs. Therefore, multidirectional embedding of R-A structure strengthened the impact properties of KSPCs when compared to those reinforced by unidirectional ones.

\section{Effect of transcrystalline layer at the interface}

In semi-crystalline polymer composites, the spherulites growth is often restricted to the lateral direction caused by heterogeneous nucleation with sufficiently high density along the interphase region [29]. Therefore, a columnar layer can be created around the fibrous reinforcements (in the transversal direction to the nucleating surface) denominated as "transcrystalline layer" (TCL). The possible formation of TCL at the fiber/matrix interface is an additional factor that could affect the mechanical properties of the SPCs under investigation.

PLM and SEM were used to verify the presence of TCL in PA6-based KSPCs. Fig. 10a illustrated representative cryogenically fractured sample of the J-A reinforced KSPCs with $15 \% \mathrm{~V}_{\mathrm{f}}$ fiber content aligned along the wale (0) direction with different magnifications applied. Fig. 10b-c evidence good interfacial bonding between the anionic PA6 matrix material and the monofilaments. There are no visible voids or cracks, neither signs of melting of filaments or their surface degradation. The conical shape of the fractured filaments is a sign of good mechanical resistance and adhesion at the matrix-filament interface.

As seen from the inset of Fig. 10d, the average thickness of the monofilament in annealed Jersey reinforcements is $17-18 \mu \mathrm{m}$. The SEM images in Fig. 10e-f demonstrate the thickness ranges of $21-22 \mu \mathrm{m}$ and $22-23 \mu \mathrm{m}$ for monofilaments in the embedded J-A and R-A structure respectively. This difference is an indirect proof for the formation of TCL of matrix PA6 material upon the PA6 monofilaments of the reinforcing textile structure. Therefore, TCL thickness of $2-3 \mu \mathrm{m}$ for Jersey and $1.5-2.5 \mu \mathrm{m}$ for Rib1 $\times 1$ reinforced KSPCs can be suggested.

\section{X-ray scattering study}

To present a study on crystalline structure and fraction of composites and their precursors, the X-ray diffraction measurements were carried out. Peak fitting was performed for deconvolution of the linear 

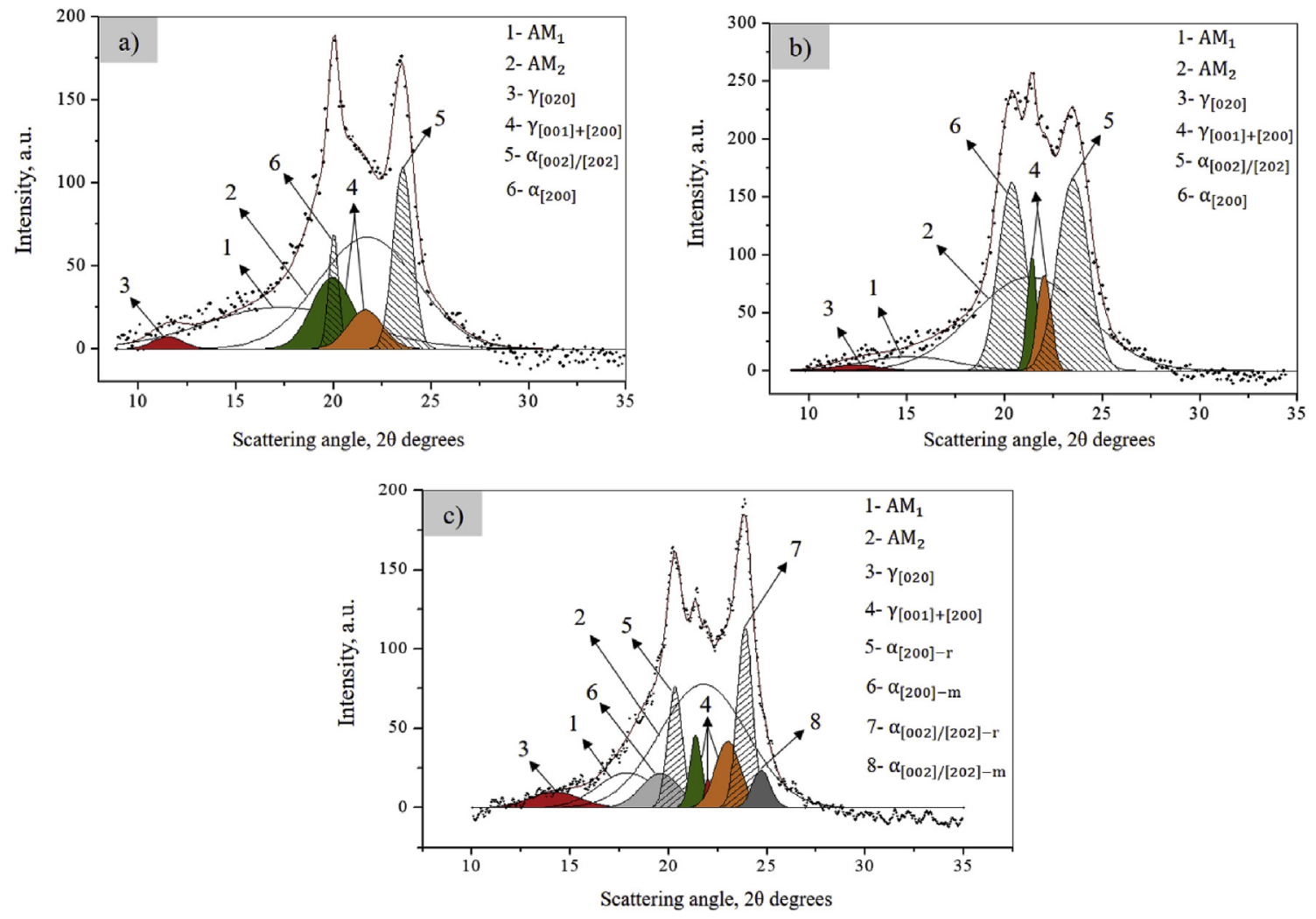

Fig. 11. WAXS patterns and their fits of SPCs building components: a) PN; b) R-A; c) PU-R-15. AM = amorphous portion.

Table 3

Data from the deconvolution of the XRD patterns of SPCs, textile structures and anionic PA6 precursors.

\begin{tabular}{lllllll}
\hline Sample & $\alpha_{\text {Total }} \%$ & $\alpha_{\text {Reinforcements }} \%$ & $\alpha_{\text {Matrix }} \%$ & $\gamma \%$ & $X_{c}^{X R D}, \%$ & $\frac{\alpha}{\gamma}$ \\
\hline MPs & 26.5 & - & - & 15.2 & 41.7 & 1.74 \\
PN & 17.4 & - & - & 17.5 & 34.9 & 1.00 \\
J-A & 41.0 & - & - & 11.8 & 52.8 & 3.47 \\
R-A & 42.9 & - & - & 10.7 & 53.6 & 4.00 \\
R & 31.0 & - & - & 9.5 & 40.5 & 3.26 \\
PU-J-15 & 31.0 & 13.0 & 18.0 & 14.9 & 45.9 & 2.08 \\
PU-J-20 & 31.8 & 10.9 & 20.9 & 19.3 & 51.1 & 1.65 \\
PU-J-25 & 33.7 & 15.4 & 18.3 & 12.5 & 46.2 & 2.69 \\
PU-R-15 & 28.4 & 8.7 & 19.7 & 15.3 & 43.7 & 1.86 \\
PM-J-15 & 28.9 & 4.7 & 24.2 & 12.7 & 41.6 & 2.28 \\
PM-R-15 & 24.7 & 7.0 & 17.7 & 21.1 & 45.8 & 1.17 \\
\hline
\end{tabular}

diffraction patterns with fitting coefficients $\mathrm{r}^{2} \approx 0.99$. Fig. 11 displays selected representative examples and Table 3 shows all data extracted after deconvolution.

In accordance with previous studies [25,30], the two peaks with $2 \theta$ at ca. $20^{\circ}$ and $23^{\circ}$ were assigned to the $\alpha$ [200] and $\alpha[002 / 202]$ crystalline planes of $\alpha$-PA6 polymorph with the monoclinic unit cell. Moreover, two Gaussian peaks corresponding to $\gamma[001]$ and $\gamma[200]$ crystalline planes were identified with $2 \theta$ being between 21 and $22^{\circ}$ that are characteristic for the PA6 $\gamma$-crystalline form with the nonhexagonal unit cell. Two wide peaks (halos), denoted by $\mathrm{AM}_{1}$ and $\mathrm{AM}_{2}$ represent the diffuse scattering of the amorphous PA6 component.

Fig. 11a and $\mathrm{b}$ show XRD patterns of the matrix PA6 (PN) and the annealed Jersey (J-A) composite components. The PN sample shows narrower $\alpha$-PA6 reflections than those of the $\gamma$-polymorph. The annealed Jersey reinforcement shows the presence of both PA6 polymorphs, the content of the $\gamma$-PA6 being less than in the isotropic PN sample. As found in previous synchrotron X-ray studies [25], this is characteristic for oriented PA6 samples, especially if they are thermally treated as in the case of J-A and R-A. Table 3 indicates that all annealed textiles display a higher crystallinity index, typically with $10-11 \%$, as compared to the non-annealed $\mathrm{J}$ and $\mathrm{R}$ samples, as well as the isotropic matrix PA6. Notably, in the J-A sample, the two oriented $\alpha$-PA6 reflections are symmetrical, which suggests the same crystallite growth along the two crystalline planes: the one of the H-bonds ( $\alpha[002 / 202])$ and that of the van der Waals interactions $(\alpha[200])$.

Since $\alpha$-PA6 in the isotropic and oriented PA6 displayed different $2 \theta$ positions, this made possible the separation of the $\alpha[200]$ and $\alpha[002 /$ 202] reflections of the isotropic matrix PA6 and those of the oriented PA6 reinforcements in the PU-R-15 sample, as seen in Fig. 10c. For the peaks of the two $\gamma$-polymorphs, however, such a separation was not straightforward. Good fits with $\mathrm{r}^{2}>0.99$ were obtained with three $\gamma$ PA6 peaks: two narrow ones of the $\gamma$ [001] and $\gamma$ [200] crystalline planes, most probably of the oriented textile and one more peak supposedly of the $\gamma$-PA6 matrix. Moreover, in the PU-R-15 composite in Fig. 10c, the two $\alpha$-reflections of the textile reinforcements are asymmetric with the $\alpha[002 / 202]$ plane becoming stronger. Since no melting of the reinforcing monofilament occurred, as shown by the microscopy study above, it can be supposed that the melting and the recrystallization of the matrix material during the laminate consolidation has led to a growth of the oriented $\alpha$-crystallites along the direction of the crystalline planes characterizing the H-bonds. Previous synchrotron X-ray scattering studies on all-polyamide composite with PA6 matrix reinforced by PA66 textiles [11] has shown that the preferential crystalline growth along this direction could be an indication, although indirect, for the possible formation of TCL of matrix material upon the textile filaments.

Table 3 shows also that in all KSPCs the $\alpha$-PA6 content in the matrix is always higher than that in the embedded textile structure. The difference between the two values seems to be dependent on the type of the knitting pattern and the alignment of the textile ply in one or more direction. The $\mathrm{X}_{\mathrm{c}}^{\mathrm{XRD}}$ values of the studied SPCs vary between $42 \%$ (PM- 
J-15) and 51\% (PU-J-20) and the $\alpha / \gamma$ ratio - between 1.2 for PM-J-15 and 2.7 for PU-J-25. Such differences can be considered significant. It seems that the different textile ply pattern and alignment can really affect the crystallization process which is expected to result in different mechanical behavior.

\section{Conclusions}

Polyamide 6 based single polymer composites reinforced by knitted structures (KSPCs) were produced by combination of powder-coating and compression molding techniques (PCCM). Two knitted architectures, namely Rib and Jersey patterns were selected and used as reinforcements after stretching-annealing procedure. The necessary PA6 microparticles from which the composite matrix ordinated were preliminarily synthesized by solution-precipitation AAROP. They showed a melting temperature lower than that of the PA6 textile reinforcements, which enabled widening of the processing window of the KSPCs consolidation. This is of prime importance for the preparation of SPCs with good mechanical performance. The flexural and impact properties of the KSPCs were studied in relation to the reinforcement architecture, fiber volume, plies orientation and stacking order. The results revealed that the J-A reinforced KSPCs, with relatively low fiber content $(15 \%)$, possess better flexural stiffness and impact behavior than the R-A reinforced ones. All KSPCs composites in this study showed higher flexural and impact properties when compared to the neat matrix.

To understand impact failure of KSPCs, the comparative studies on the tensile and compression stiffness of knitted reinforcements were carried out. DMA studies showed despite the position of the neutral plane, J-A had slightly higher compression modulus than R-A structures. Thus, the superior impact strength of the J-A reinforced KSPCs could be depended on the tensile stiffness of the knitted reinforcements in all directions. Finite element analysis of the elastic behavior of knitted reinforcements proved that the loops in the J-A structures equally distribute the equivalent tensile stress along loop parts. The "von Mises stresses" were more concentrated on loop legs in R-A reinforcements. Furthermore, the loops of J-A structures supported more the tensile loads than R-A structures. PLM and SEM studies provided indirect proof for the existence of a transcrystalline layer at the matrixreinforcement interface, which was supported by the results of the deconvolution of the XRD patterns of KSPCs and neat textile reinforcements. Further improvement of the SPCs mechanical behavior will require new architecture of the reinforcements, optimization of their surface and studying the interlaminar shear strength of the SPCs as a function of ply amount and alignment.

\section{Acknowledgements}

This work was partially financed by FEDER funds through the COMPETE program and by national funds through FCT - Foundation for Science and Technology within the project POCI-01-0145-FEDER007136. SDT thanks FCT for his Ph.D. Grant SFRH/BD/94759/2013. NVD thanks for the financial support of FCT in the frames of the strategic project UID/CTM/50025/2013. Finally, ZZD is thankful to FCT for the SFRH/BSAB/130271/2017 personal research grant. All authors gratefully acknowledge the support of the project TSSiPRO-NORTE-010145-FEDER-000015 funded by the regional operational program NORTE 2020, under the PORTUGAL 2020 Partnership Agreement, through the European Regional Development Fund.
Polym Sci 2002;86:1899-903.

[2] Hine PJ, Astruc A, Ward IM. Hot compaction of polyethylene naphthalate. J Appl Polym Sci 2004;93:796-802.

[3] Lacroix F v, Werwer M, Schulte K. Solution impregnation of polyethylene fibre/ polyethylene matrix composites. Composer Part A Appl. Sci. Manuf. 1998;29:371-6.

[4] Ward IM, Hine PJ. The science and technology of hot compaction. Polymer 2004; 45:1413-27.

[5] Gong Y, Yang G. Single polymer composites by partially melting recycled polyamide 6 fibers: preparation and characterization. J Appl Polym Sci 2010;118:3357-63.

[6] Bhattacharyya D, Maitrot P, Fakirov S. Polyamide 6 single polymer composites. Express Polym Lett 2009;3:525-32.

[7] Alcock B, Cabrera NO, Barkoula N-M, Wang Z, Peijs T. The effect of temperature and strain rate on the impact performance of recyclable all-polypropylene composites. Compos B Eng 2008;39:537-47.

[8] Khondker OA, Fukui T, Inoda M, Nakai A, Hamada H. Fabrication and mechanical properties of aramid/nylon plain knitted composites. Composer Part A Appl. Sci. Manuf. 2004;35:1195-205.

[9] Yao D, Li R, Nagarajan P. Single-polymer composites based on slowly crystallizing polymers. Polym Eng Sci 2006;46:1223-30.

[10] Gong Y, Liu A, Yang G. Polyamide single polymer composites prepared via in situ anionic polymerization of $\varepsilon$-caprolactam. Composer Part A Appl. Sci. Manuf. 2010;41:1006-11.

[11] Dencheva N, Denchev Z, Pouzada AS, Sampaio AS, Rocha AM. Structure-properties relationship in single polymer composites based on polyamide 6 prepared by inmold anionic polymerization. J Mater Sci 2013;48:7260-73.

[12] Dencheva N, Vale D, Denchev Z. Dually reinforced all-polyamide laminate composites via microencapsulation strategy. Polym Eng Sci 2017;57:806-20.

[13] Ramakrishna S. Energy absorption characteristics of knitted fabric reinforced epoxy composite tubes. J Reinforc Plast Compos 1995;14:1121-41.

[14] Huang Z-M. Progressive flexural failure analysis of laminated composites with knitted fabric reinforcement. Mech Mater 2004;36:239-60.

[15] Kannan TG, Wu CM, Cheng KB. Effect of different knitted structure on the mechanical properties and damage behavior of Flax/PLA (Poly Lactic acid) double covered uncommingled yarn composites. Compos B Eng 2012;43:2836-42.

[16] Putnoki I, Moos E, Karger-Kocsis J. Mechanical performance of stretched knitted fabric glass fibre reinforced poly (ethylene terephthalate) composites produced from commingled yarn. Plast. Rubber Compos. 2013:40-6.

[17] Karger-Kocsis J, Yuan Q, Mayer J, Wintermantel E. Transverse impact behavior of knitted carbon-fiber fabric-reinforced thermoplastic composite sheets. J Thermoplast Compos Mater 1997;10:163-72.

[18] Pandita SD, Falconet D, Verpoest I. Impact properties of weft knitted fabric reinforced composites. Compos Sci Technol 2002;62:1113-23.

[19] Khondker OA, Leong KH, Herszberg I, Hamada H. Impact and compression-afterimpact performance of weft-knitted glass textile composites. Composer Part A Appl. Sci. Manuf. 2005;36:638-48.

[20] Aktaş A, Tercan M, Aktaş M, Turan F. Investigation of knitting architecture on the impact behavior of glass/epoxy composites. Compos B Eng 2013;46:81-90.

[21] Brêda C, Dencheva N, Lanceros-Méndez S, Denchev Z. Preparation and properties of metal-containing polyamide hybrid composites via reactive microencapsulation. J Mater Sci 2016;51:10534-54.

[22] Oliveira F, Dencheva N, Martins P, Lanceros-Méndez S, Denchev Z. Reactive microencapsulation of carbon allotropes in polyamide shell-core structures and their transformation in hybrid composites with tailored electrical properties. Express Polym Lett 2016;10:160-75.

[23] Dencheva N, Denchev Z, Lanceros-Méndez S, Ezquerra Sanz T. One-step in situ synthesis of polyamide microcapsules with inorganic payload and their transformation into responsive thermoplastic composite materials. Macromol Mater Eng 2016;301:119-24.

[24] Rusu G, Ueda K, Rusu E, Rusu M. Polyamides from lactams by centrifugal molding via anionic ring-opening polymerization. Polymer 2001;42:5669-78.

[25] Dencheva N, Nunes T, Oliveira MJ, Denchev Z. Microfibrillar composites based on polyamide/polyethylene blends. 1. Structure investigations in oriented and isotropic polyamide 6. Polymer 2005;46:887-901.

[26] Menard KP. Dynamic mechanical analysis: a practical introduction. CRC press; 2008.

[27] Zienkiewicz OC, Taylor RL, Zienkiewicz OC, Taylor RL. The finite element method. McGraw-hill London; 1977.

[28] Dowling NE. Mechanical behavior of materials. Pearson; 2012.

[29] Gao C, Yu L, Liu H, Chen L. Development of self-reinforced polymer composites. Prog Polym Sci 2012;37:767-80.

[30] Samon JM, Schultz JM, Hsiao BS. Study of the cold drawing of nylon 6 fiber by insitu simultaneous small-and wide-angle X-ray scattering techniques. Polymer 2000;41:2169-82.

[31] Karger-Kocsis J, Czigany T, Mayer J. Fracture behaviour and damage growth in knitted. Illumination 1996;25:109-14.

[32] Strong AB. Fundamentals of composites manufacturing: materials, methods and applications. Society of Manufacturing Engineers; 2008.

\section{References}

